\title{
Condensation of HFE-7100 vapor in a loop heat pipe having a curvilinear fin
}

\author{
Yuriy Lyulin ${ }^{1,2, *}$ Munko Gonchikzhapov ${ }^{2}$, Irina Tueva $^{2}$ and Igor Marchuk ${ }^{1,2,3}$ \\ ${ }^{1}$ Kutateladze Institute of Thermophysics SB RAS, 630090, Novosibirsk, Russia \\ ${ }^{2}$ Novosibirsk State University, 2, Pirogov Ave., 630090, Novosibirsk, Russia \\ ${ }^{3}$ Novosibirsk State Agrarian University, 160, Dobrolyubov Ave., 630039, Novosibirsk, Russia
}

\begin{abstract}
Vapor condensation of the HFE-7100 in loop heat pipe was studied experimentally and theoretically. Numerical calculations of the vapor condensation on the curvilinear fin have been performed. Numerical, theoretical and experimental data are in a good agreement. Minimal condensate film thickness on the top of the fin has been determined and increases monotonously with the increase in the temperature drop.
\end{abstract}

\section{Introduction}

Condensation of a pure vapor with a small value of the mass flow is used in many industrial applications. Specifically, it plays an important role in thermal control systems for space applications. For instance, such systems as heat pipes, loop heat pipes, capillary pumped loops and mechanically pumped loops are widely used on satellites to ensure the heat transfer from the core module equipment's to the external radiators [1]. The main component of such devices is condenser. The latent heat of the fluid vaporization is used to transfer the heat efficiently at a nearly constant temperature. The miniaturization of the system requires new studies on the two-phase flows and a better understanding of the condensation phenomenon at this scale. The major goal of the studies is an increase of the performance of condensers. Using of internal curvilinear fins provide an essential heat transfer enhancement [2,3]. Gregorig [4] first derived a theoretical model for condensation on curvilinear fin with account of surface tension. The fin was described by equation for a spiral with variable direction of rotation. Subsequent models for stationary vapour film condensation on parametric family of curvilinear fins with power dependence of the curvature have been presented in [5-8]. Some experimental results related to the film wise vapour condensation on curvilinear fins are presented in $[9,10]$. Description of various theoretical models and experimental results on film wise condensation are presented in several books and reviews [11-14].

Correlations used for the design of condensers for space applications, have been developed and tested only under the ground conditions. It is known that length of the smooth in-tube condenser under microgravity conditions significantly exceeds that for the similar condenser under ground conditions, $[15,16]$. Both, theoretical modelling and quantitative experimental results give a better understanding the physical phenomena and

* Corresponding author: 1yulin@itp.nsc.ru 
lead to correlations and design rules for the next generation of the space exploration of thermal control systems.

The main goals of this work are experimental testing of a new design condenser model with longitudinal fin for loop heat pipe and theoretical study of vapor condensation of the HFE-7100 on curvilinear fin surface.

\section{Experimental setup}

For the studies of vapor condensation in the condenser with curvilinear fins a new experimental rig was created, see Fig. 1. The experimental rig consists of the following components: test cell (1); high precision liquid pump (2); evaporator (3); cooling water liquid flow meter (4); working liquid flow meter (5); heating water liquid flow meter (6); personal computer (7); thermocouples (8); pressure sensor (9); vapor flow meter (10); pressure controller (11); vacuum pump (12); control and data acquisition system (13); CCD camera (14); heat insulated box (15); heater fan (16); power supply (17); thermostats $(18,19)$; liquid container (20); valves (21-22). Before starting the experiment, air is pumped out from the experimental loop (EC) by a vacuum pump (Agilent IDP-15,12 on Fig.1). Further, the operating liquid from the container is injected into the EC using a liquid pump (ISMATEC REGLO-Z, 2 on Fig.1). The liquid fills the lower part of the condenser and half of the volume of the evaporator (3 on Fig.1). Plate heat exchanger Alfa Laval AXF10-10H$\mathrm{F}$ is used as the vapor generator-evaporator. The heat exchanger has two independent lines, between which heat exchange takes place. The heat exchanger is installed in vertical position. The first line is used in the contour of loop heat pipe for generating vapor. The liquid from the test cell under the action of hydrostatic pressure fills the half of the first line. Hot water is pumped through the second line, thereby heating, an intense evaporation or boiling of the fluid occur in the first line. The temperature of water is controlled by thermostat № 2 (Huber, MPC-K6, 19 on Fig.1) and does not exceed $80^{\circ} \mathrm{C}$. The temperature is measured on input and output of the second line. The thermostat 2 has an internal fluid flow meter (6 on Fig.1). As a result of intense evaporation or boiling liquid vapor generates at the top of the second line and the pressure increases. Vapor from the evaporator moves to the test cell where the condensation occurs on the cooled curvilinear fin. The temperature of the condenser is controlled by pumping water from thermostat № 1 (Huber, MPC-K6, 18 on Fig.1). Vapor flow in the test cell is carried out by the pressure difference between the evaporator and the test cell. The pressure in the test cell is controlled by the condenser temperature and pressure controller (Bronkhorst El-Press, 10 on Fig.1) of vacuum pump. Vapor flow rate is measured by mass flow metter (Bronkhorst FLOW-DP F-201D, 11 on Fig.1) at the entrance to the test cell. Test cell pressure is measured by the pressure meter (WIKA p-30, 9 on Fig.1). The test cell with all monitoring sensors and devices is placed in the heat insulated casing (15 on Fig. 1$)$. In this casing a special thermal fan (17 on Fig. 1$)$ is placed. The temperature inside the casing is kept above the saturation temperature of $1-3^{\circ}$ $\mathrm{C}$ to prevent uncontrolled condensation which may occur in the used monitoring devices and connecting tubes. As a result the uncontrolled condensation causes the pressure and the flow fluctuations, which can terminate the experiment. Condensation occurs only inside the test cell. Special valve before the vacuum pump is installed which cuts off the line after completion of the experiment, providing a contour sealing (22 on Fig.1). Container volume is $500 \mathrm{ml}$. Position of meniscus is fixed by CCD camera (14 on Fig.1). Temperature readings were recorded by measuring module NI TB 9214 (13 on Fig.1). All sensors of pressure and of flow are working in the analog mode, the control of which was produced using two DAQ NI 6001 modules (13 on Fig.1). Pressure in the system without liquid was increased by approximately 1 mbar for 24 hours. 


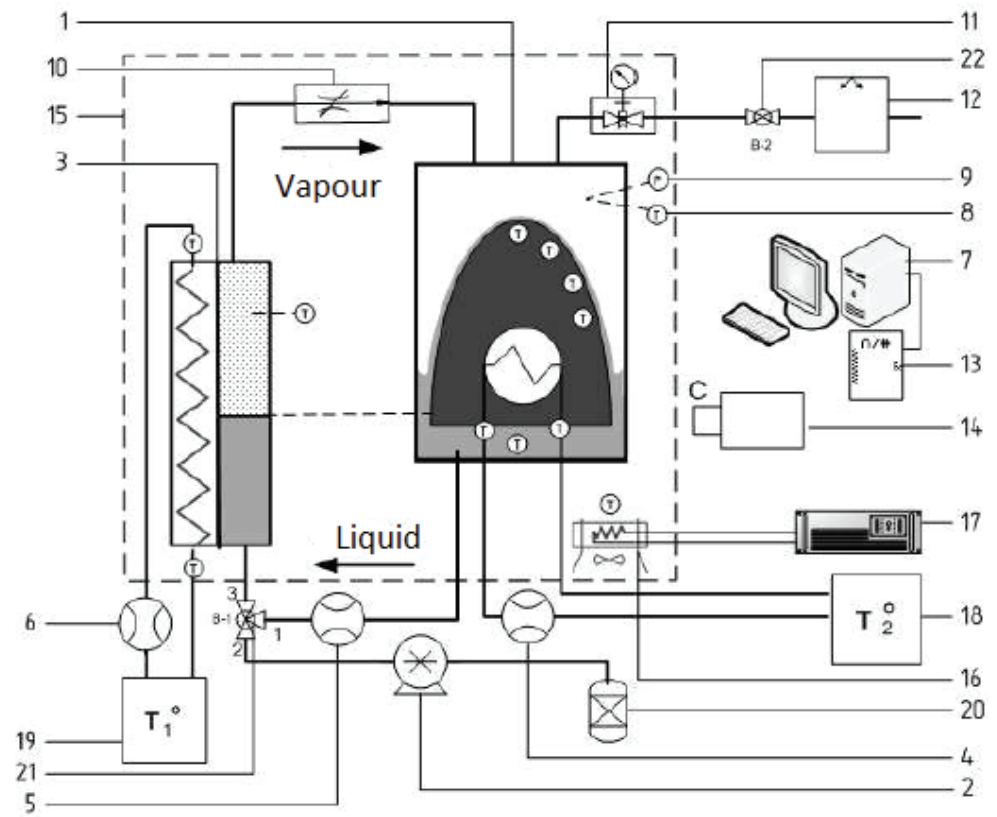

Fig. 1. Scheme of the experimental setup.

The most important part of the experimental rig is the test cell. The design and photo of the test cell with a longitudinal fin are shown in Fig. 2. The test cell consists of the condenser in shape of the longitudinal fin, vapor chamber composed of transparent walls and distribution cambers for cooling water. The condenser fin is made of highly thermally conductive material $(\mathrm{Cu})$. The height of the fin is $54 \mathrm{~mm}$, width $30 \mathrm{~mm}$ and length $200 \mathrm{~mm}$. Cooling water from thermostat controls the temperature of the condenser. The cooling water is pumping through the distribution chambers and special channels in the fin body with a diameter of $5 \mathrm{~mm}$. The distribution chambers are fitted at the housing face of test cell and have a water temperature measurement. Attachment of the distribution chambers with the condenser is made with the help of two bolts (M8 with $300 \mathrm{~mm}$ length) through housing face walls. Hermeticity of the test cell is achieved by using silicon sealant and rubber seal. The temperature of the condenser is measured with help of six thermocouples $(\mathrm{OD}=0.5 \mathrm{~mm})$ that installed by three pieces on each end of the fin. Thermocouples are installed in the fin body through the front sides and holes with a diameter of $1.5 \mathrm{~mm}$. The implementation depth of the thermocouple tips is $100 \mathrm{~mm}$ and $30 \mathrm{~mm}$ for each side, correspondently. The holes are located on the top, in the middle and at the bottom of the fin at the distance of $5 \mathrm{~mm}$ from the surface of condensation. The housing of the test cell is made of transparent polycarbonate walls. The distance between the side walls and fin surface can be varied in the range of $0.5-1.5 \mathrm{~mm}$. Vapor is supplied into the test cell through a stainless steel tube with inside diameter of $14 \mathrm{~mm}$ and length of $200 \mathrm{~mm}$. The tube is placed at the distance of $20 \mathrm{~mm}$ over the top of the fin. Special holes with diameter of $2 \mathrm{~mm}$ with the step of $10 \mathrm{~mm}$ are located on the side of the tube providing uniform distribution of the vapor inside the test cell. The temperature of the vapor, condensed liquid and cooling water are measured by the thermocouples with diameter of $1.5 \mathrm{~mm}$ that embedded in the test cell using special fitting. Pressure sensor is installed in top cover. Fluid line for pumping out of the condensed liquid is connected from the bottom of test cell. 


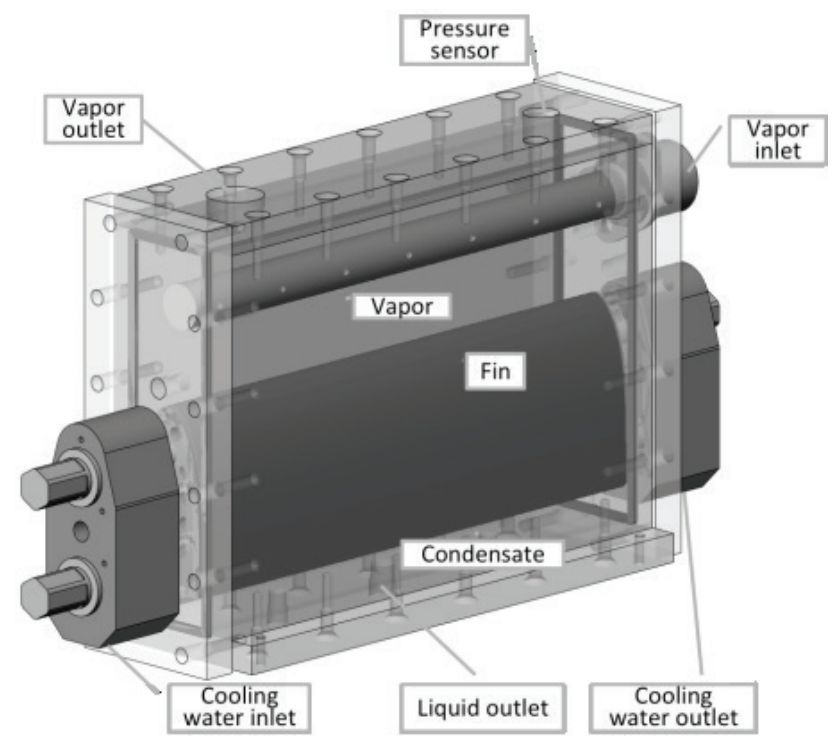

Fig. 2. Design of the test cell.

The average heat-transfer coefficient is determined by formula: $Q \quad Q / A \cdot\left[\begin{array}{ll}\tau_{s} & T_{\mu}\end{array}\right]$, where $q$ is heat flux, $A$ is the area of condenser surface, $T_{s}$ is the vapor saturation temperature, $T_{w}$ is the average temperature of condenser fin. The temperature of saturated vapor is determined using the dependence of saturated vapor temperature and pressure (P-T dependence). The pressure in the test cell is measured by high-precision sensor of pressure. Temperature of vapor is measured by carefully calibrated thermocouple. Difference between temperature measured by thermocouple and temperature determinated by P-T dependence should be no more than $0.1 \mathrm{~K}$. Thus it is assumed that the vapor moving from the evaporator has no significant impurities affecting the condensation process. The temperature of the condenser fin is defined as the mean value of six thermocouples mounted in the body of the fin. The heat flux is determined by the formula: $q \quad r \cdot G_{1}$, where $r$-specific heat of vaporization, $G_{v}$-rate of condensed vapor. The method is based on measuring mass flow rate of vapor at the inlet of the test cell.

\section{Results}

Experiments are carried at saturation temperature $30,12 \mathrm{C}^{\circ}$ relevant to pressure 354 mbar. Pure HFE-7100 is used as the working liquid. The difference between the saturation and wall temperatures are changed during the experiments in range from 0.22 to $4.67 \mathrm{~K}$. Shape of fin is calculated using the theoretical model and optimized to obtain the maximum condensate flow rate from the fin surface for given geometric parameters and microgravity conditions. The given generatrix curve of the fin surface is a solution of the corresponding variational problem presented in $[4,7]$. The curvature of the generated curve of the fin is

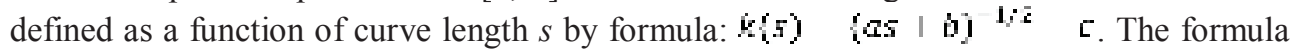
constants of defined fin have the following values: $a=6.769519 \mathrm{e}+000, \mathrm{~b}=4.339554 \mathrm{e}$ $005, \mathrm{c}=-2.762646 \mathrm{e}+001$, the curvature at the fin top $-1 \mathrm{~mm}^{-1}$, the length of the generatrix curve $\mathrm{S}=60 \mathrm{~mm}$. Full rotation of the curve is equal to $90^{\circ}$.

The dependence of the average heat transfer coefficient on the temperature drop is presented in Fig. 3. The temperature drop between the surface and vapor temperature varies from $0.1 \mathrm{~K}$ to $5 \mathrm{~K}$. The diagram shows the experimental (curve 1) numerical (curve 2) and 
theoretical (curve 3) results. Numerical calculations of the vapor condensation of pure HFE-7100 liquid on the curvilinear fin have been performed using the theoretical model described in [7, 10]. The theoretical heat transfer coefficient is calculated by Nusselt formula for condensation on the vertical square plate: $Q \quad 4 / 3 \sqrt{\lambda^{2} \rho^{2} r g i 4 \mu \Delta T L}$, where $\lambda$ - heat conductivity of the liquid, $\mathrm{W} /(\mathrm{m} \cdot \mathrm{K}) ; \rho$ - liquid density, $\mathrm{kg} / \mathrm{m}^{3} ; r$ - latent heat of vaporization, $\mathrm{J} / \mathrm{kg} ; \boldsymbol{\rho}-$ gravitational acceleration, $\mathrm{m} / \mathrm{s}^{2} ; \mu-$ dynamic viscosity $\mathrm{Pa} \cdot \mathrm{s} ; \Delta T \quad\left(T ; T_{w}\right)$-difference between the saturation and wall temperatures, K. $2-$ linear size is chosen using the assumption that the surface area of the plate equals to the half surface of the longitudinal fin.

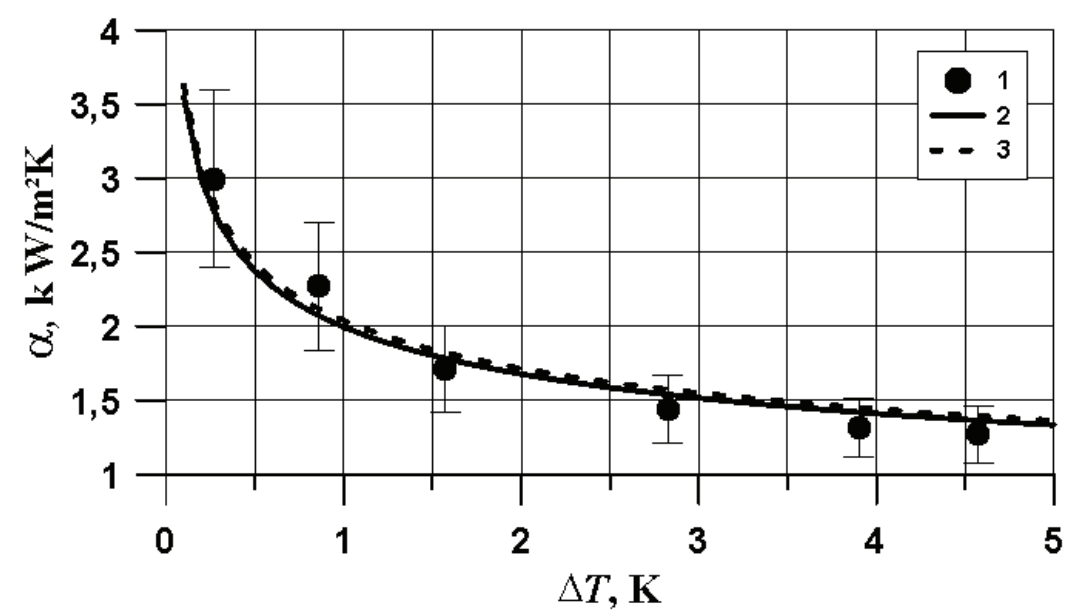

Fig. 3. Dependence of the average heat transfer coefficient on the temperature drop. 1 - experimental data, 1 - numerical calculation, 2 - calculation by Nusselt formula.

The heat transfer coefficients display the usual trend that expected for the condensation of the pure vapor on vertical wall. The heat transfer coefficient is reduced monotonically with the increase of the temperature drop. The values of the average heat transfer coefficient are in the range of 1.27-2.9 $\mathrm{kW} / \mathrm{m}^{2} \mathrm{~K}$ for experimental data and 1.3-3.6 kW/ $\mathrm{m}^{2} \mathrm{~K}$ for the numerical and theoretical ones, Fig. 3. The distribution of the condensate film thickness for the temperature drop $\Delta \mathrm{T}=5 \mathrm{~K}$ is presented in Fig. 4. Calculated minimal condensate film thickness is at the top of the fin and changes from $3 \mu \mathrm{m}$ to $11.4 \mu \mathrm{m}$ for the given temperature range, see Fig 4b. Minimal condensate film thickness increases monotonously with the increase in the temperature drop.
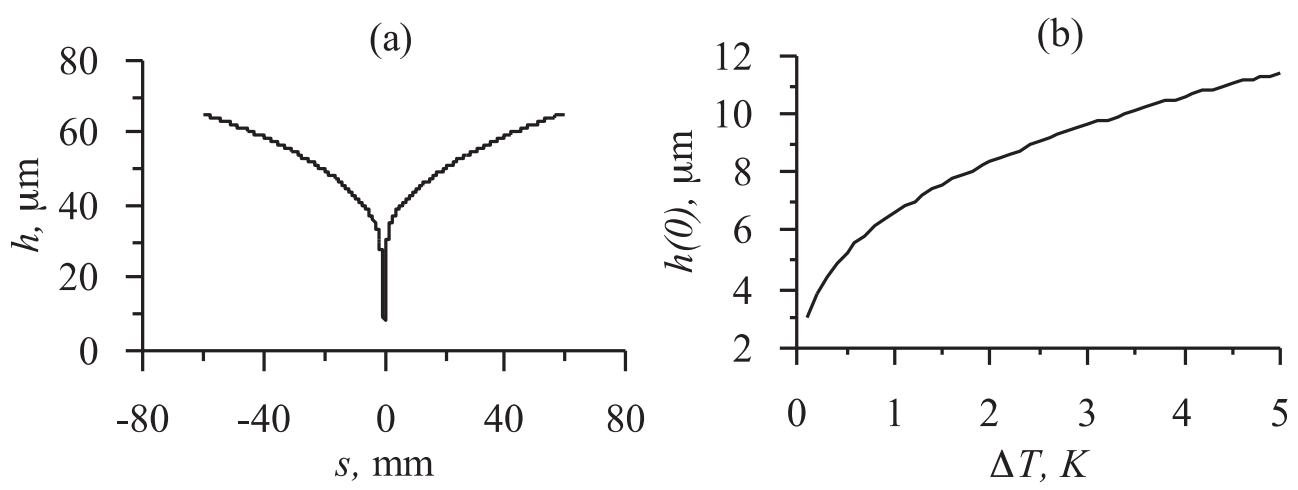

Fig.4. Condensate film thickness. (a)-along the fin surface, $\Delta \mathrm{T}=5 \mathrm{~K}$; (b) - on the fin top. 


\section{Conclusions}

New experimental rig and numerical calculations for study of film vapor condensation HFE-7100 on the curvilinear fins has been performed. The results of experiment and calculations of condensation of HFE-7100 on the longitudinal fin have been obtained for different values of the temperature difference between saturation temperature and fin surface temperature. The calculated heat transfer coefficient is in the range of 1.3-3.6 $\mathrm{kW} / \mathrm{m}^{2} \mathrm{~K}$, the experimental data is in the range $1.27-2.9 \mathrm{~kW} / \mathrm{m}^{2} \mathrm{~K}$. Numerical, theoretical and experimental data are in a good agreement. Minimal condensate film thickness on the top of the fin has been calculated and changes from $3 \mu \mathrm{m}$ to $11.4 \mu \mathrm{m}$. It is shown the minimal condensate film thickness increases monotonously with the increase in the temperature drop.

The authors gratefully acknowledge the support of this work by the Ministry of Education and Science of the Russian Federation (Agreement 14.616.21.0016, project identifier RFMEFI61614X0016).

\section{References}

1. V. Serin, P. Lavieille, M. Miscevic, Microgravity Science and Technology, 21, 1, 103109 (2009)

2. O.A. Kabov, D.R. Kolyukhin, I.V. Marchuk, J.-C. Legros, Journal of Engineering Thermophysics 12, 1, 199-210 (2003)

3. R.L. Webb, Principles of Enhanced Heat Transfer, p. 556 (1994)

4. R. Gregorig, Zeitschrift für angewandte Mathematik und Physik Bd. 5, 1, 36 - 49 (1954)

5. C. Zener and A. Lavi, Journal of Heat Transfer 96, 205-209 (1974)

6. T. Adamek, Warme - und Stoffubertragung 15, 255 - 270 (1981)

7. I.V. Marchuk and O.A. Kabov, Encyclopedia of Two-Phase Heat Transfer and Flow II: Special Topics and Applications, Vol. 3, Chapter 5, pp. 133-176 (2015)

8. I.V. Marchuk and O.A. Kabov, Doklady Physics, 61, 1, 19-23 (2016)

9. A. Glushchuk, I.V. Marchuk and O.A. Kabov, Journal Microgravity Science and Technology 23, 1, 65-74 (2011)

10. I.V. Marchuk, A.V. Gluschuk and O.A. Kabov, Technical Physics Letters 32, 5, 388391 (2006)

11. J.R. Thome, Engineering Data Book III (2008)

12. V.G. Rifert, H.F. Smirnov, Condensation Heat Transfer Enhancement, p. 371 (2004)

13. J. Rose, Enhanced condensation heat transfer, 49, 3, 626-635 (2006)

14. A. Cavallini, G. Censi, D. Del Col, L. Doretti, G.A. Longo, L. Rossetto, C. Zilio, International Journal of Refrigeration 26, pp. 373-392 (2003)

15. E. G. Keshok, M. S. Sadeghipour, Aste Astronautica 10, 7, 505-511 (1983)

16. I. Da Riva, A. Sanz, Microgravity Science and Technology 4, 3, 179-187 (1991) 